\title{
Effect of ammonia on the immune response of mud crab (Scylla paramamosain) and its susceptibility to mud crab reovirus
}

\section{Chang-Hong Cheng, Hong-Ling Ma, Yi-Qin Deng, Juan Feng, Yu- Kun Jie, Zhi-Xun Guo*}

Key Laboratory of South China Sea Fishery Resources Exploitation \& Utilization, Ministry of Agriculture, South China Sea Fisheries Research Institute, Chinese Academy of Fishery Sciences, Guangzhou, Guangdong 510300, China, PR China

Keywords Scylla paramamosain; MCRV infection; Ammonia exposure; Oxidative stress

\begin{abstract}
Ammonia is one of the major environmental pollutants that affect the growth and physiological functions of organisms. In the present study, the effects of ammonia on the immune response and pathogen resistance of mud crab reovirus (MCRV) in mud crab were investigated. Mud crab were exposed to four different ammonia concentrations $\left(0,2.5,5\right.$ and $10 \mathrm{mg} \mathrm{L}^{-1}$ ammonia- $\left.\mathrm{N}\right)$ for $7 \mathrm{~d}$. The result showed that aspartate aminotransferase (AST) and alanine aminotransferase (ALT) activity significantly increased after 5 and $10 \mathrm{mg} \mathrm{L}^{-1}$ ammonia exposure. The hepatopancreas superoxide dismutase (SOD), catalase (CAT), and total antioxidative capacity (T-AOC) in ammonia- $\mathrm{N}$ group were significantly lower than those in the control group, while the levels of malondialdehyde (MDA) were significantly higher than those in the control group. Significant reductions in total hemocyte counts (THC) were observed after ammonia exposure. After 7d ammonia exposure, mud crabs were injected $100 \mu \mathrm{L}$ MCRV at $10^{5}$ copies/g body weight. The mortality of mud crabs in ammonia- $\mathrm{N}$ group were significantly higher than those in the control group. All these results suggested that ammonia in water caused a depression in the immune response, and increased susceptibility to MCRV infection.
\end{abstract}

*Corresponding author. Tel./fax: +86 2089108331 E-mail addresses:

15603064226@163.com (Z.-X. Guo) 


\section{Introduction}

Mud crab (Scylla paramamosain) is one of the most important aquaculture crustaceans in China. The mud crab aquaculture production exceeded 158 thousand tons. However, mud crab aquaculture faces threats due to bacteria or viruses' infection, causing the largest economic losses (Guo et al., 2013). Mud crab reovirus (MCRV) has caused about 70\% mortality in the mud crab aquaculture (Weng et al., 2007). It infects connective tissues in the hepatopancreas, gills, and intestines (Deng et al., 2012). Many studies have been undertaken on MCRV genome structure, purification, detection and crab innate defenses (Deng et al., 2012; Huang et al., 2012; Liu et al., 2017). However, until now there are not any treatments to control this pathogen.

Under certain environmental conditions, mud crab and MCRV can co-exist without outbreak of the disease. However, when aquaculture environment changed, it could easily lead to disease outbreak (Lotz et al., 2005; Moser et al., 2012). Ammonia is a major aquatic environmental pollutant. It may build up to high concentrations in culture system due to excess feeding. High concentrations of ammonia can accumulate in the body fluids, affecting survival, growth, physiological functions and immune defenses (Eddy, 2005; Hong et al., 2007). Many studies suggested that oxidative stress is one of the toxicity mechanisms of ammonia on aquatic animals (Zheng et al., 2014; Cheng et al., 2015). Oxidative stress can damage important biomolecules and cause oxidative damage. Previous study reported that ammonia exposure led to DNA damage and cell death in mud crab (Cheng et al., 2019). Increased concentrations of environmental ammonia have been reported to suppress the immune ability, and increase vulnerability to disease (Ackerman et al., 2006). However, there are very few works on the effects of environmental stress on infection, particularly MCRV in mud crab. In the present study, we investigated the effects of ammonia exposure on the immune response and pathogen resistance of MCRV in mud crab. This study will contribute to the development of strategies to control the disease of mud crab.

\section{Materials and Methods}

Mud crabs ( $56 \pm 5.4 \mathrm{~g}$ ) were obtained from a mud crab farm in Taishan (Guangdong, China). It was kept in tanks for one week before the experimental treatments. It were fed with oyster meat twice daily. During the experimental period, water temperature, salinity, $\mathrm{pH}$ and dissolved oxygen was $25 \pm 3^{\circ} \mathrm{C}, 10 \%, 7.8$, and above $6.0 \mathrm{mg} \mathrm{L}^{-1}$, respectively.

Two hundred and forty mud crabs were selected for ammonia exposure. Previous study reported that total ammonia $96 \mathrm{~h}$ LC50 value for mud crab was approximately $60 \mathrm{mg} \mathrm{L}^{-1}$ (Peng et al., 2018). In this study, mud crabs were exposed to at ammonia- $\mathrm{N}$ concentrations of $0,1 / 24,1 / 12$ and $1 / 6$ of the $96 \mathrm{~h} \operatorname{LC} 50\left(0,2.5,5\right.$ and $\left.10 \mathrm{mg} \mathrm{L}^{-1}\right)$. There were three replicates for each group. The ammonia- $\mathrm{N}$ concentration of each exposure group was adjusted to the desired concentration by adding $\mathrm{NH}_{4} \mathrm{Cl}$ to $10 \%$ saltwater. The water was exchanged daily. After exposure for $7 \mathrm{~d}$, nine mud crabs were selected randomly from each group. Hemolymph of individual mud crab was withdrawn from the base of the third pereiopod. After collecting hemolymph, hepatopancreas were separated for the following analysis.

After $7 \mathrm{~d}$ ammonia exposure, mud crabs of each group were selected for MCRV challenge. Each mud crab was injected with $100 \mu \mathrm{L}$ MCRV at $10^{5}$ copies/g body weight. After $0,6,12,24,36,48$, and $72 \mathrm{~h}$, the mortality was examined.

Hemolymph samples were placed on a hemocytometer to count cells with a light microscope (Olympus).

Hepatopancreas samples were homogenized in ice-cold phosphate buffer. The homogenates were centrifuged at $3000 \mathrm{~g}$ for $20 \mathrm{~min}$. Then, the supernatants were collected for the measurement of AST, ALT, CAT, SOD, T-AOC, and MDA using commercially available kits (Jiancheng Institute of Biotechnology, Nanjing, China) according the manufacturer's protocols. Protein concentration of hepatopacreatic homogenate was measured by the Bradford method (Bradford, 1976). AST and ALT activity were detected by the method of Cheng et al. (2018). CAT activity was assayed according to the method of Aebi (1984) by measuring the residual $\mathrm{H}_{2} \mathrm{O}_{2}$ absorbance. SOD activity was assayed according to the method of Peskin and Winterbourn (2000), based on the oxidation of 
epinephrine adrenochrome transition by the enzymes. T-AOC were analyzed according to the method of Jia et al. (2015). MDA content was assayed according to the method of Ohkawa et al. (1979) by using the thiobarbituric acid reactive species assay.

Date were given as means \pm standard deviation. For all analyses, Levene's and ShapiroWilk's tests were used to verify the homogeneity and normality of variance, respectively. A one-way analysis of variance (ANOVA) was used to determine whether there are any statistically significant differences between the means of two or more independent (unrelated) groups, followed by Duncan's multiple range tests using SPSS 18.0 software (SPSS; Chicago, IL). A significant difference was considered at the $\mathrm{P}<0.05$ level.

\section{Results}

The effect of ammonia exposure on THC was showed in Figure 1. Significant reductions in THC were observed after ammonia exposure. The lowest of THC was in the $10 \mathrm{mg} \mathrm{L}^{-1}$ ammonia- $\mathrm{N}$ group.

Compared to the control group, ALT activity in $2.5 \mathrm{mg} \mathrm{L}^{-1}$ ammonia- $\mathrm{N}$ group did not change (Figure 2A). ALT activity significantly increased after 5 and $10 \mathrm{mg} \mathrm{L}^{-1}$ ammonia-N group. Compared to the control group, AST activity significantly increased after ammonia exposure (Figure 2B).

There was no significant difference of SOD activity between the control group and 2.5 $\mathrm{mg} \mathrm{L}^{-1}$ ammonia-N group (Figure 3). SOD activity significantly decreased at 5 and $10 \mathrm{mg}$ $\mathrm{L}^{-1}$ ammonia-N group. A significant decrease of CAT activity was observed at 2.5, 5 and 10 $2.5 \mathrm{mg} \mathrm{L}^{-1}$ ammonia- $\mathrm{N}$ group with the value of 0.67 -fold, 0.61 -fold and 0.41 -fold lower than those of the control group, respectively (Figure 4). T-AOC levels was lower in mud crab exposed to $2.5,5$ and $10 \mathrm{mg} \mathrm{L}^{-1}$ ammonia- $\mathrm{N}$ compared to the control group (Figure 5). Compared to the control group, MDA levels significantly increased after ammonia exposure (Figure 6). The highest of MDA levels were observed at $10 \mathrm{mg} \mathrm{L}^{-1}$ ammonia-N group.

Mud crab began to die at $12 \mathrm{~h}$ after MCRV infection (Figure 7). The mortality of mud crab in all groups increased with infection time. The mortality of mud crab in the control group was significantly lower than that of the ammonia- $\mathrm{N}$ group at $72 \mathrm{~h}$ after MCRV infection.

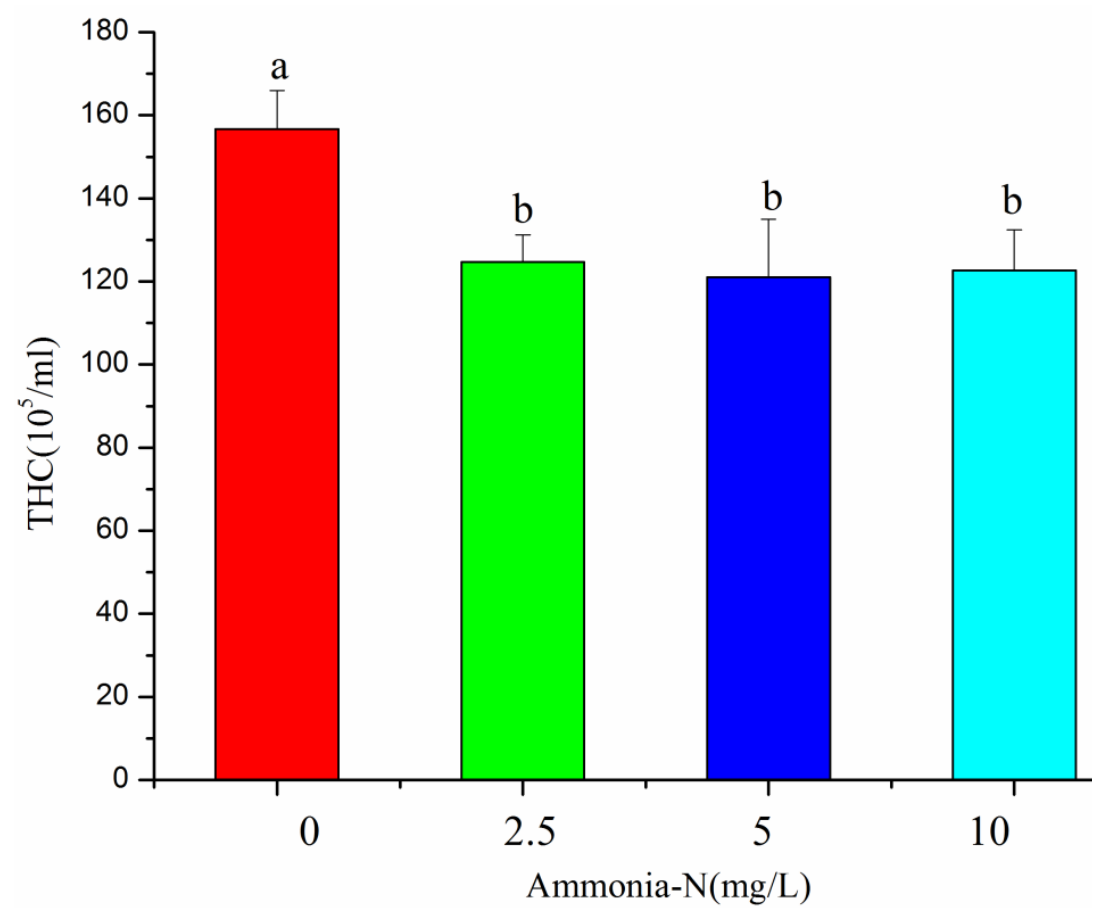

Figure 1 Effects of ammonia exposure on THC. Data shown as the mean $\pm S D(N=6)$. Different letters indicated significant differences between control group and ammonia treatment group $(P<0.05)$. 

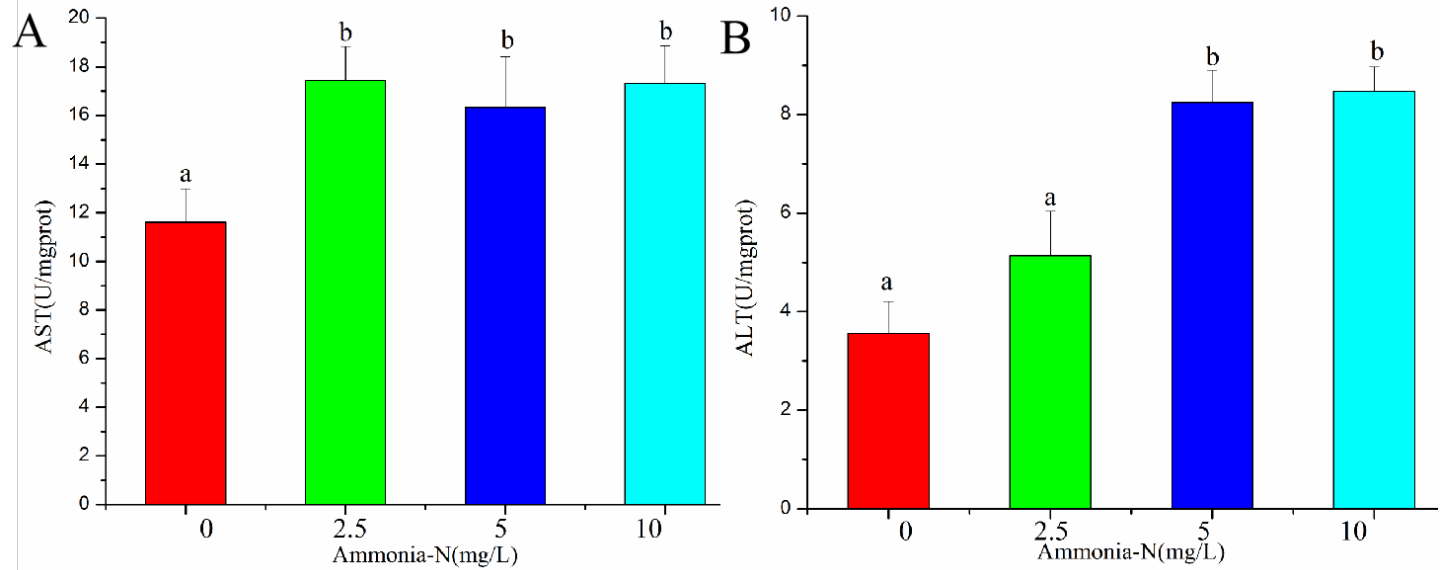

Figure 2 Effects of ammonia exposure on the activity of ALT (A) and AST (B). Data shown as the mean $\pm \mathrm{SD}(\mathrm{N}=6)$. Different letters indicated significant differences between control group and ammonia treatment group $(P<0.05)$.

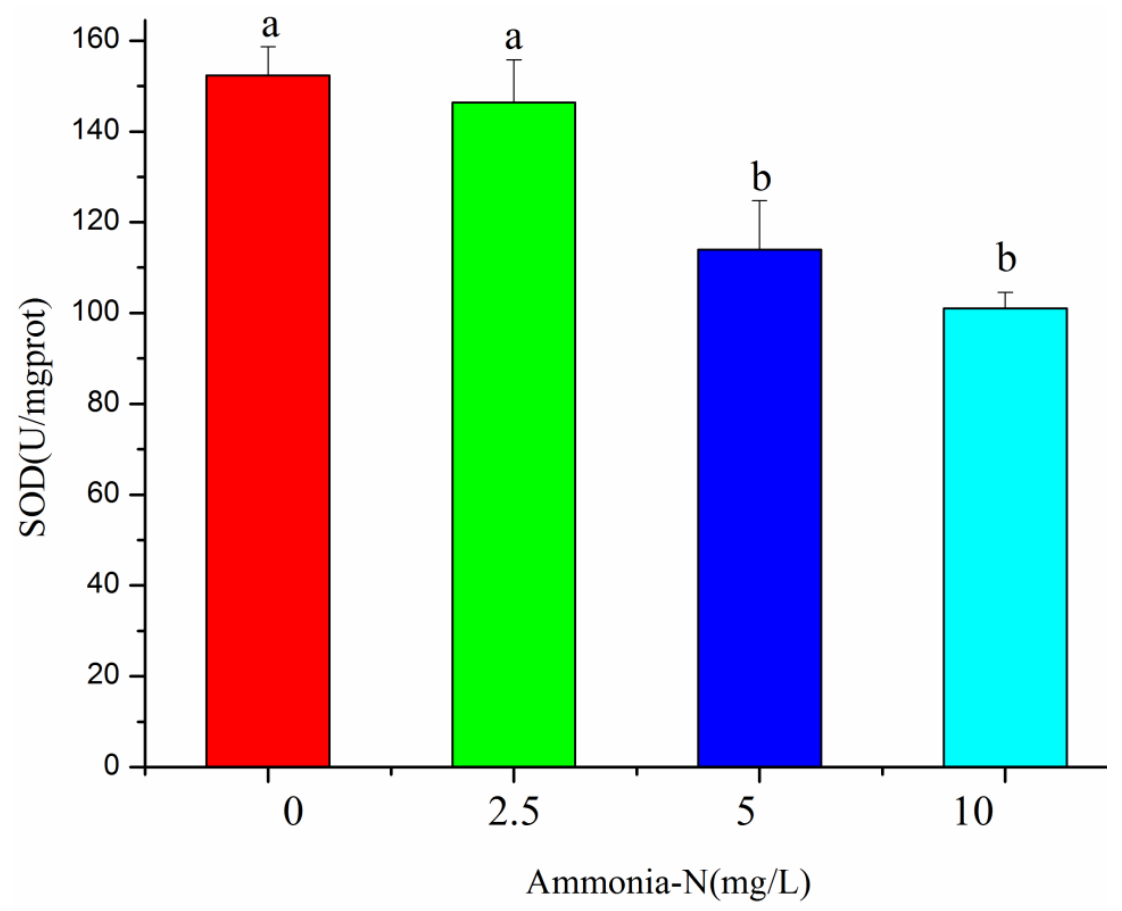

Figure 3 Effects of ammonia exposure on the activity of SOD. Data shown as the mean \pm SD $(\mathrm{N}=6)$. Different letters indicated significant differences between control group and ammonia treatment group $(P<0.05)$. 


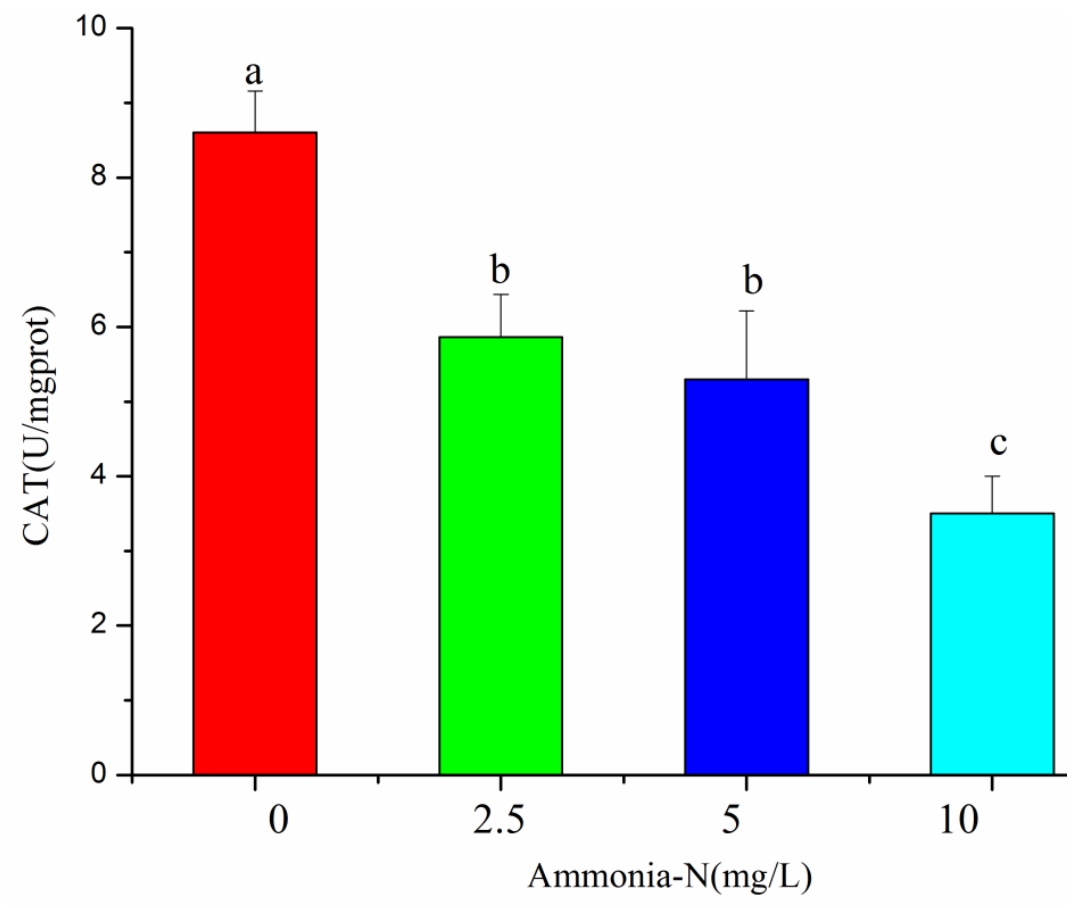

Figure 4 Effects of ammonia exposure on the activity of CAT. Data shown as the mean \pm SD $(\mathrm{N}=6)$. Different letters indicated significant differences between control group and ammonia treatment group $(P<0.05)$.

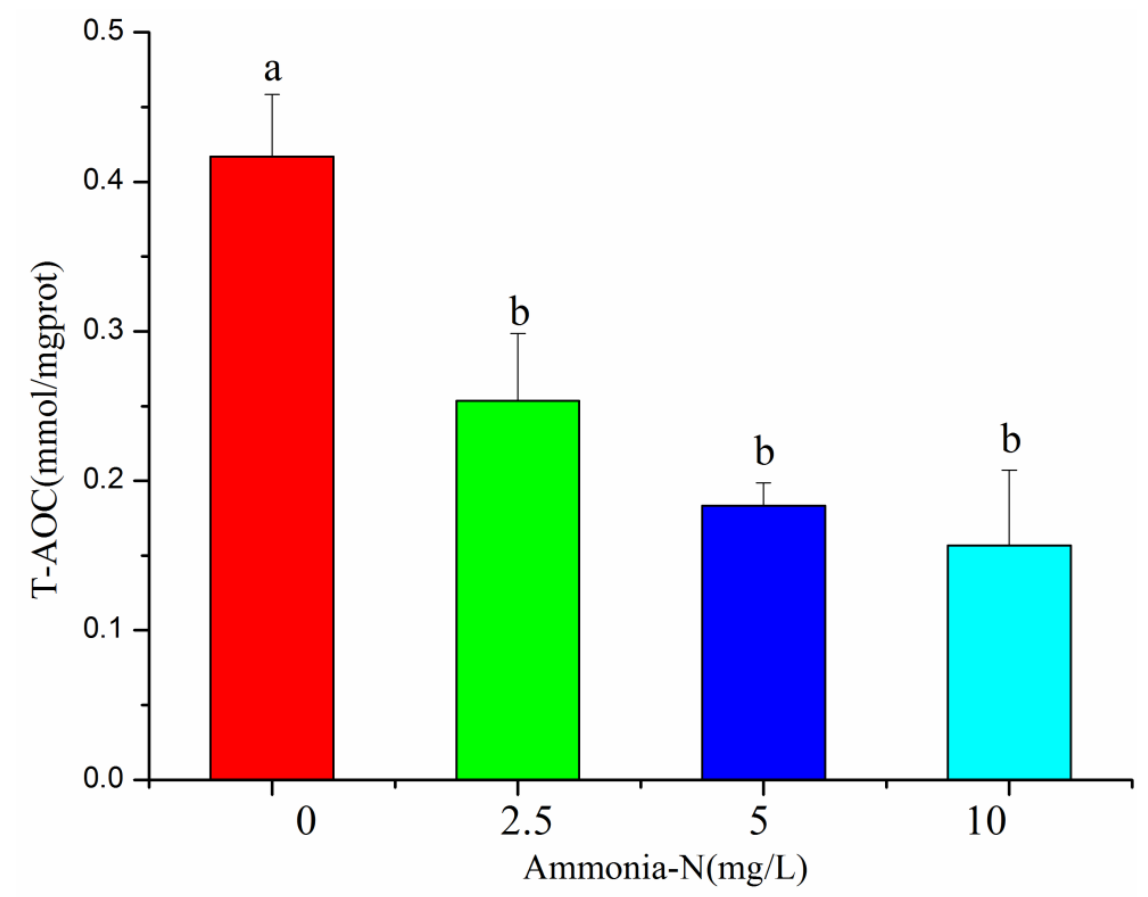

Figure 5 Effects of ammonia exposure on T-AOC levels. Data shown as the mean \pm SD $(\mathrm{N}=6)$. Different letters indicated significant differences between control group and ammonia treatment group $(P<0.05)$. 


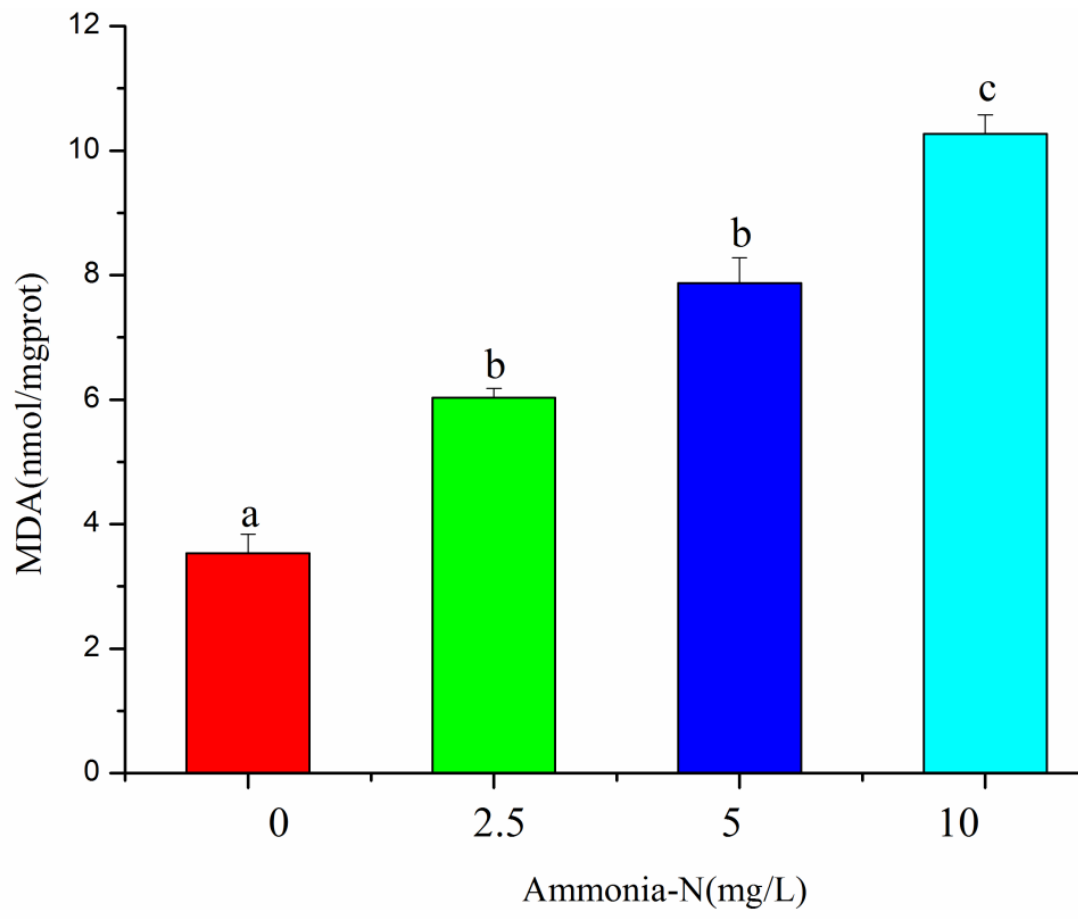

Figure 6 Effects of ammonia exposure on MDA levels. Data shown as the mean \pm SD $(\mathrm{N}=6)$. Different letters indicated significant differences between control group and ammonia treatment group $(P<0.05)$.

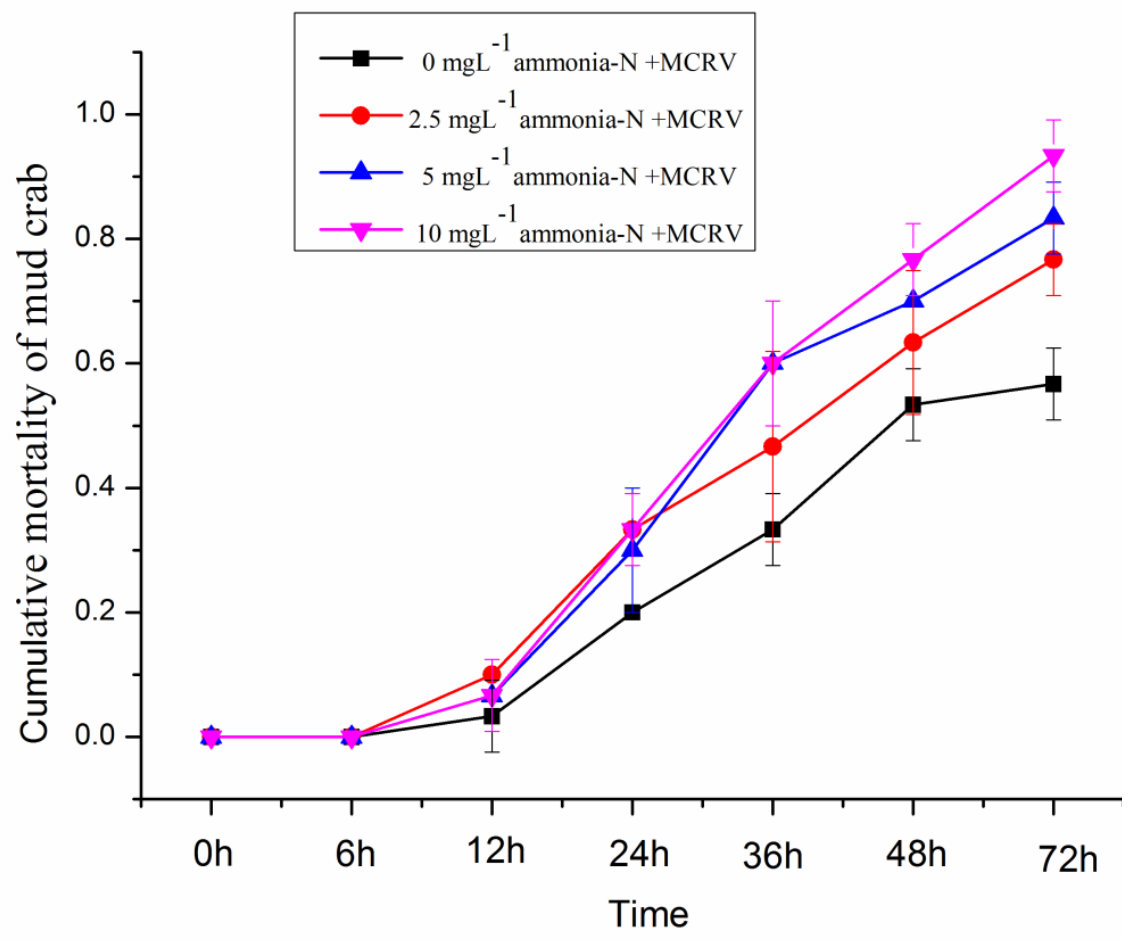

Figure 7 Cumulative mortality of mud crab after MCRV infection at different time intervals $(0,6,12,24,36,48$ and $72 \mathrm{~h})$. 


\begin{abstract}
Discussion
\end{abstract}
Ammonia is one of the most important limiting factors in aquatic system. Accumulation of ammonia may threaten the healthy of cultured aquatic animals. As a crustacean, mud crab has a non-specific immune system in response to environmental stress. Hemocytes play an important role in physiology and immune response. THC could be easily affected by environmental stress. A low THC value in aquatic organisms is strongly correlated with a great sensitivity to pathogens (Cheng et al., 2018). In the present, the THC decreased after ammonia exposure. The result was consistent with research on Macrobrachium rosenbergii (Cheng and Chen, 2002) and Penaeus japonicus (Jiang et al., 2004) following exposure to ammonia. The decrease of THC could injure immune function (Qin et al., 2012). Hepatopancreas play important roles in metabolism and detoxification. Environmental stress can lead to hepatotoxicity. AST and ALT are the most significant enzymes involved in protein and amino acid metabolism. AST and ALT activities are considered as a functional response of extra energy requirements and the increasing rate of metabolism to cope with environmental stress (Giannini et al., 2005). They also regarded as biomarkers for liver damage. Abbas (2006) reported an increase in the activities of ALT and AST in Cyprinus carpio due to ammonia toxicity. Similarly, the present study showed that ALT and AST activities significantly increased after ammonia exposure. The increase in the activity of these enzymes may be the resultant of the hepatotoxic under ammonia exposure.

MDA is widely used as a marker of lipid peroxidation. Many studies have demonstrated that ammonia exposure can induce an increase in MDA levels (Jin et al., 2017; Cheng et al., 2019). These results were agreement with our data that MDA levels significantly increased after ammonia exposure, suggesting that ammonia exposure can lead to the peroxidation of membrane polyunsaturated fatty acids. The increase in MDA levels may result from the generation of excessive ROS (Halliwell, 1999). Previous research reported that high concentration of ammonia could trigger the release of ROS (Cheng et al., 2017). Under normal physiological conditions, the antioxidant defense system can eliminate excessive ROS. SOD and CAT are the fist line antioxidant defenses that directly scavenge ROS. SOD can catalyze the conversion of $\mathrm{O}_{2}^{-}$to $\mathrm{H}_{2} \mathrm{O}_{2}$ and $\mathrm{O}_{2}$. CAT can degrade the $\mathrm{H}_{2} \mathrm{O}_{2}$ to $\mathrm{H}_{2} \mathrm{O}$ and $\mathrm{O}_{2}$. However, under environmental stress, the antioxidant defense system were destroyed, and the detoxification function of the organism was suppressed (Jia et al., 2015). Zhang et al. (2019) suggested that reported that the antioxidant enzyme activities, including SOD, CAT, and GPX, were inhibited in Megalobrama amblycephala after chronic ammonia, leading to the excessive accumulation of MDA. Our data showed that the activity of SOD and CAT significantly decreased after ammonia exposure. T-AOC can reflect the total antioxidant ability of the body. In the present study, T-AOC levels were inhibited after ammonia exposure. These results suggested that the total antioxidant ability to eliminate reactive free radicals was destroyed, which can lead to oxidative damage.

MCRV has caused largest economic losses in mud crab farming. Viral infection can affect disease outbreak (Sun et al., 2015). When environmental stress depresses the immune response of the organism, it could accelerate viral amplification, leading disease outbreak (Penaranda et al., 2009). Previously study reported that Litopenaeus vannamei after ammonia exposure lowered the disease resistance to WSSV (Jiang et al., 2004). In the present study, cumulative mortality of mud crab in ammonia-N group after MCRV infection was significantly higher than these in the control group. The reason may be explained as that ammonia exposure damaged the immune system of mud crab, which speeds up the rate of viral replication, leading to mud crab death (Moser et al., 2012; Sun et al., 2015). In conclusion, the present study documented the effects ambient ammonia on the immune response and pathogen resistance of MCRV in mud crab. Ammonia exposure can increase AST and ALT activities, and disturb the physiological response in mud crab. Ammonia exposure also inhibited SOD and CAT activity, and led to oxidative stress. Oxidative stress induced by ammonia exposure can decrease THC. Ammonia exposure decreased the resistance of mud crab to MCRV infection by a reduction in immune responses. 


\section{Acknowledgements}

This research was supported by China Agricultural Research System (CARS-48), Science and Technology Program Project of Guangzhou (201904010327), the scientific and technological innovation team of China Academy of Fishery Sciences (2020TD42), Basic and applied basic research fund of Guangdong Province (2019A1515011548), Key Laboratory of Tropical Marine Bio-resources and Ecology, South China Sea Institute of Oceanology (2019011007).

\section{References}

Abbas H.H., 2006. Acute toxicity of ammonia to common carp fingerlings (Cyprinus carpio) at different $\mathrm{pH}$ levels. Pak. J. Biol. Sci., 9: 2215-2221. https://doi.org/10.3923/pjbs.2006.2215.2221.

Ackerman P.A., Wicks B.J., Iwama G.K. and D.J. Randall, 2006. Low levels of environmental ammonia increase susceptibility to disease in Chinook salmon smolts. Physiol.Biochem. Zool. 79: 695-707. https://doi.org/10.1086/504615

Aebi, H., 1984. Catalase in vitro. Methods Enzymol. 105: 121-126. https://doi.org/ 10.1016/S0076-6879(84)05016-3

Bradford, M.M., 1976. A rapid and sensitive method for the quantitation of microgram quantities of protein utilizing the principle of protein-dye binding. Anal. Biochem. 72:248254. https://doi.org/10.1016/0003-2697(76)90527-3

Cheng, C.H., Guo, Z.H., Luo, S.W. and A.L.Wang, 2018. Effects of high temperature on biochemical parameters, oxidative stress, DNA damage and apoptosis of pufferfish (Takifugu obscurus). Ecotoxicol. Environ. Saf. 150: 190-198. https://doi.org/10.1016/j.ecoenv.2017.12.045.

Cheng, C.H., Ma, H.L., Su, Y.L., Deng, Y.Q., Feng, J., Xie, J.W., Chen, X.L. and Z.X., Guo, 2019. Ammonia toxicity in the mud crab (Scylla paramamosain): the mechanistic insight from physiology to transcriptome analysis. Ecotoxicol. Environ. Saf. 15: 9-16. https://doi.org/10.1016/j.ecoenv.2019.04.033

Cheng, C.H., Yang, F.F., Ling, R.Z., Liao, S.A., Miao, Y.T., Ye, C.X. and A.L. Wang, 2015. Effects of ammonia exposure on apoptosis, oxidative stress and immune response in pufferfish (Takifugu obscurus). Aquat. Toxicol. 164: 61-71. https://doi.org/10.1016/j.aquatox.2015.04.004

Cheng, W.T. and J.C. Chen, 2002. The virulence of enterococcus to freshwater prawn Macrobrachium Rosenbergii and its immune resistance under ammonia stress. Fish Shellfish Immunol. 12(2): 97-109. https://doi.org/10.1006/fsim.2001.0363

Deng, X.X., Lu, L., Ou, Y.J., Su, H.J., Li, G. and Z.X. Guo, 2012. Sequence analysis of 12 genome segments of mud crab reovirus (MCRV), Virology. 422: 185-194. https://doi.org/10.1016/j.virol.2011.09.029

Eddy, F.B., 2005. Ammonia in estuaries and effect on fish. J. Fish Biol. 67: 1495-1513. https://doi.org/10.1111/j.1095-8649.2005.00930.x

Giannini, E.G., Testa, R. and V. Savarino, 2005. Liver enzyme alteration: a guide for clinicians.CMAJ, 172 (3): 367-379. https://doi.org/10.1503/cmaj.1040752

Guo, Z.X., He, J.G., Xu, H.D. and S.P. Weng, 2013. Pathogenicity and complete genome sequence analysis of the mud crab dicistrovirus-1. Virus Res. 171, 8-14. https://doi.org/10.1016/j.virusres.2012.10.002

Halliwell, B., 1999. Antioxidant defence mechanisms: from the beginning to the end (of the beginning), Free. Radic. Res. 31: 261-272. https://doi.org/10.1080/10715769900300841

Hong, M., Chen, L., Sun, X., Gu, S., Lu, Z. and C. Yong, 2007. Metabolic and immune responses in Chinese mitten-handed crab (Eriocheir sinensis) juveniles exposed to elevated ambient ammonia. Comp. Biochem. Physiol. C 145: 363-369. https://doi.org/10.1016/j.cbpc.2007.01.003

Huang, Z.W., Deng, X.X., Li, Y.Y., Su, H.J., Li, K.P., Guo, Z.X., Zheng, P.R., Xu, H.D., He, J.G., Zhang, Q.F. and S.P. Weng, 2012. Structural insights in to the classification of mud crab reovirus. Virus Res. 166(1-2): 116-20. https://doi.org/10.1016/j.virusres.2012.02.025 
Jia, R., Han, C., Lei, J.L., Liu, B.L., Huang, B., Huo, H.H. and S.T., Yin, 2015. Effects of nitrite exposure on haematological parameters, oxidative stress and apoptosis in juvenile turbot (Scophthalmus maximus). Aquat Toxicol. 169: 1-9. https://doi.org/10.1016/j.aquatox.2015.09.016

Jiang, G.J., Yu, R.C. and M.J. Zhou, 2004. Modulatory effects of ammonia-N on the immune system of Penaeus japonicus to virulence of white spot syndrome virus. Aquaculture. 241(1):61-75. https://doi.org/10.1016/j.aquaculture.2004.08.020

Jin, J., Wang, Y., Wu, Z., Hergazy, A., Lan, J., Zhao, L., Liu, X., Chen, N. and L. Lin, 2017. Transcriptomic analysis of liver from grass carp (Ctenopharyngodon idellus) exposed to high environmental ammonia reveals the activation of antioxidant and apoptosis pathways. Fish Shellfish Immunol. 63: 444-451. https://doi.org/ 10.1016/j.fsi.2017.02.037

Liu, S.S., Chen, G.X., Xu, H.D., Zou, W.B., Yan, W.R., Wang, Q.Q., Deng, H.W., Zhang, H.Q., Yu, G.J., He, J.G. and S.P. Weng, 2017. Transcriptome Analysis of Mud Crab (Scylla Paramamosain) Gills in Response to Mud Crab Reovirus (MCRV). Fish Shellfish Immunol. 60: 545-553. https://doi.org/10.1016/j.fsi.2016.07.033

Lotz, J.M., Anton, L.S. and M.A., Soto, 2005. Effect of chronic Taura syndrome virus infection on salinity tolerance of Litopenaeus vannamei. Diseases of Aquatic Organisms 65, 75-78. https://doi.org/10.3354/dao065075

Moser, J.R., Galván Álvarez, D.A., Cano, F.M., Garcia, T.E., Coronado Molina, D.E., Clark, G.P., Marques, M.R.F., Magallón Barajas, F.J. and J.H. López, 2012. Water temperature influences viral load and detection of White Spot Syndrome Virus (WSSV) in Litopenaeus vannamei and wild crustaceans. Aquaculture. 326-329: 9-14. https://doi.org/10.1016/j.aquaculture.2011.10.033

Ohkawa, H., Ohishi, N., Yagi, K., 1979. Assay for lipid peroxides in animal tissues by thiobarbituric acid reaction. Anal. Biochem. 95: 351-358. https://doi.org/10.1016/00032697(79)90738-3

Penaranda, M.M.D., Purcell, M.K. and G. Kurath, 2009. Differential virulence mechanisms of infectious hematopoietic necrosis virus in rainbow trout (Oncorhynchus mykiss) include host entry and virus replication kinetics, J. Gen. Virol. 90 (9): 2172-2182. https://doi.org/10.1099/vir.0.012286-0

Peskin, A.V. and C.C. Winterbourn, 2000. A microtiter plate assay for superoxide dismutase using a water-soluble tetrazolium salt (WST-1). Clin. Chim. Acta. 293: 157-166. https://doi.org/10.1016/S0009-8981(99)00246-6

Peng, J.H., Chen, L.Y., Cheng, C.H., Feng, J., Ma, H.L. and Z.X., Guo, 2018. Acute toxicity of ammonia nitrogen to Scylla paramamosain and its influence on immune factors in serum. Progress in Fishery Sciences. https://doi.org/10.19663/j.issn2095-9869. 20170907001

Qin, Q., Qin, S., Wang, L. and W. Lei,2012. Immune responses and ultrastructural changes of hemocytes in freshwater crab Sinopotamon henanense exposed to elevated cadmium. Aquat. Toxicol. https://doi.org/106-107. 10.1016/j.aquatox.2011.08.013

Sun, C.B., Wang, G. and S.F. Chan, 2015. Effects of artificial infection of Litopenaeus vannamei by Micrococcus lysodeikticus and WSSV on the activity of immunity related enzymes. Fish Shellfish Immunol. 46: 778-786. https://doi.org/10.1016/j.fsi.2015.06.029 Weng, S.P., Guo, Z.X., Sun, J.J., Chan, S.M. and J.G. He, 2007. A reovirus disease in cultured mud crab, Scylla serrata, in southern China. J. Fish Dis. 30: 133-139. https://doi.org/10.1111/j.1365-2761.2007.00794.x

Zhang, W.X., Xia, S.L., Zhu, J., Miao, L.X., Ren, M.C., Lin, Y., Ge, X.P. and S.M. Sun, 2019. Growth performance, physiological response and histology changes of juvenile blunt snout bream, Megalobrama amblycephala exposed to chronic ammonia. Aquaculture. 506: 424-436. https://doi.org/10.1016/j.aquaculture.2019.03.072

Zheng, G.H., Liu, C.M., Sun, J.M., Feng, Z.J. and C. Cheng, 2014. Nickel-induced oxidative stress and apoptosis in Carassius auratus liver by JNK pathway. Aquat. Toxicol. 147:105-111. https://doi.org/10.1016/j.aquatox.2013.12.015 